\title{
Study on Mechanical Properties of Basalt Fiber Reinforced Concrete
}

\author{
Jian-jun Li ${ }^{1, a}$, Zhi-ming Zhao ${ }^{2, b}$ \\ ${ }^{1}$ College of Mechanic and Electronic, Shaanxi University of Science and Technology, Xi'an \\ 710021, Shaanxi, China \\ ${ }^{2}$ College of Mechanic and Electronic, Shaanxi University of Science and Technology, Xi'an \\ 710021, Shaanxi, China \\ aEmail: lijianjun@sust.edu.cn, ${ }^{\text {b} E m a i l: ~ z h a o z h i m i n g @ s u s t . e d u . c n, ~}$
}

Keyword: Basalt; Fiber; Properties; Concrete

\begin{abstract}
As a new type of green material with excellent physical and chemical properties and mechanical properties. Basalt fiber are widely used in the field of civil construction. The present status of the research and engineering applications of basalt fiber in concrete were summarized.The advantage of application of basalt fiber in concrete was discussed.In addition some problems for the study and application of basalt fiber in concrete were brought forward.
\end{abstract}

\section{Introduction}

Basalt continuous fiber reinforced composite material strength, chemical stability, electrical insulation properties are superior to glass fiber reinforced materials, in large part to replace glass fiber, carbon fiber, widely used in aerospace, petrochemical, construction, automotive, etc.field; basalt melting process there is no discharge of boron and alkali metal oxides, the basalt fiber manufacturing process environmentally benign, non-industrial waste, no emissions of harmful gases into the atmosphere. The basalt fiber are the 21st century a new type of environmentally friendly fibers.

Basalt fiber composite materials in civil engineering applications include chopped basalt fiber, basalt fiber sheet material, profiles, plates, ribs (rods) material, cable materials, as a new building material, the application includes the followingaspects: (1) as modified concrete admixtures in the field of concrete enhanced. (2) in the construction, repair, reinforce and update the field instead of the Restoration materials of carbon fiber reinforced beams, columns, plates, wall structure, bridges, tunnels, dams and other civil engineering can also be reinforced, especially for seismic reinforcement. (3) in the field of road construction as a geogrid material. With a clear price advantage compared to carbon fiber, basalt fiber, and thus has broad prospects for development in the field of engineering applications.

\section{Physical and chemical properties of basalt fiber}

Basalt fiber has high density .it's tensile strength at break is close to the E-glass fibers. It's modulus of elasticity is higher than that of $\mathrm{E}$ glass fibers and close to $\mathrm{S}$ glass fibers. The heatof resistance is significantly superior to the glass fibers c carbon fibers and aramid fibers.it may be used at $650{ }^{\circ} \mathrm{C}$ long-term. the physical properties of basalt fiber with other fibers are shown in Table 1-1. 
Tab1-1The physical performance of basalt fiber compares with other fibers

\begin{tabular}{|c|c|c|c|c|c|}
\hline Performance & $\begin{array}{l}\text { Basalt } \\
\text { fiber }\end{array}$ & S glassfibe & E glassfibe & Carbonfiber & Aramidfiber \\
\hline Densit $\left(\mathrm{g} / \mathrm{cm}^{3}\right)$ & 2.65 & $2.46 \sim 2.49$ & $2.55 \sim 2.62$ & 1.78 & 1.44 \\
\hline $\begin{array}{c}\text { Tensilestrength } \\
\text { (MPa) }\end{array}$ & $\begin{array}{l}3000 \sim \\
3500\end{array}$ & $4590-4830$ & $3100-3800$ & $\begin{array}{l}2500 \sim \\
3500\end{array}$ & $\begin{array}{c}2758 \sim \\
3034\end{array}$ \\
\hline $\begin{array}{l}\text { Modulus of elasticity } \\
\text { (Gpa) }\end{array}$ & $\begin{array}{l}79.3 \sim \\
93.0\end{array}$ & $88 \sim 91$ & $76 \sim 78$ & $230 \sim 240$ & $124 \sim 131$ \\
\hline Elongatio(\%) & 3.2 & 5.6 & 4.7 & - & 2.3 \\
\hline Temperature $\left({ }^{\circ} \mathrm{C}\right)$ & $-260 \sim 500$ & 300 & $-60 \sim 60$ & 500 & 250 \\
\hline $\begin{array}{l}\text { Thermalconductivity } \\
(\mathrm{W} / \mathrm{m} \cdot \mathrm{k})\end{array}$ & $\begin{array}{l}0.031 \sim \\
0.038 \sim\end{array}$ & - & $\begin{array}{l}0.034 \\
0.04\end{array}$ & - & - \\
\hline
\end{tabular}

Tab1-2 chemical stability of Basalt continuous fiber

\begin{tabular}{ccccc}
\hline Diameter $(\mu \mathrm{m})$ & $\mathrm{H}_{2} \mathrm{O}$ & $(0.5 \mathrm{H}) \mathrm{NaOH}$ & $(2 \mathrm{H}) \mathrm{NaOH}$ & $(2 \mathrm{H}) \mathrm{HCl}$ \\
\hline 17 & 99.63 & 98.3 & 92.8 & 76.9 \\
12 & 99.7 & 98.9 & 90.7 & 49.9 \\
9 & 99.6 & 94.6 & 83.3 & 38.8 \\
\hline
\end{tabular}

Basalt fiber has high corrosion resistance and chemical stability in corrosive media (such as a salt solution、 an acid solution、 particularly in the alkali solution) (Table 1-2). Compared with the metal. basalt fiber will not be corroded. Compared with glass fiber.basalt fiber is alkali-resistant material.

In short. The basalt fiber has good physical and chemical properties. Compared to glass fiber.basalt fiber has a high mechanical strength 、 heat resistance 、 acid and alkali resistance v sound insulation velectrical insulation and other excellent performance for composite materials. It is a low-cost 、 high-performance new quality reinforced material. Basalt fiber's surface is smooth. The resistance of the gas and liquid through is maximum.it can be used at temperature of $650^{\circ} \mathrm{C}$. with the chemical stability of acid and alkali and water. basalt fiber is high-quality materials in corrosive gases and smoke layer filtering and corrosive liquid filtration It can compensate for the strength of the fiber and it can compensate for the poor shortcomings of fiber with low-elastic modulus and low-temperature resistance. it can be recycled importantly. But also it can make up for the defects of asbestos and other mineral fibers which are threating to the environment of human being.

\section{Reinforcing mechanism of basalt fiber}

Basalt fiber belongs pozzolan, it has higher activity index, and good interfacial bonding properties with cement, it is a good cement matrix composite reinforcement. as a brittle material, in the Cement will generate a large number of pores and cracks when It is casting and curing in the interior and the surface, $\mathrm{SiO}_{2}$ and $\mathrm{AL}_{2} \mathrm{O}_{3}$ that basalt fiber contained can react with alkaline substances which inside the cement , to produce hydrated silicon calcium and hydrated calcium aluminate gel and other substances, the pores and cracks of the cement matrix can be effective repaired, so that the mechanical properties of the cement matrix can be improved.

Basalt fiber reinforced concrete is a concrete composite material which is formed by mixing basalt continuous fibers with appropriate content and method. In order to improve the brittleness of concrete, cracking and the disadvantages of poor corrosion resistance, with concrete as matrix, and the mechanical properties of basalt fiber, made of basalt fiber reinforced concrete material, while 
retaining the advantages of high compressive strength of concrete at the same time, significantly improve the tensile strength, abrasion resistance and impact resistance and other properties. Basalt fiber can play reinforcing, toughening and reinforcing and prolong life effect of reinforcement in concrete engineering.

Basalt fiber in concrete has obvious crack resistance and toughening effect, (I) it is mainly manifested in elastic modulus and high tensile strength, in the concrete from microcosmic reinforced enhancement, the cracks from coupling effect, restrain the crack extension, an increase of concrete energy absorption and improve the toughness of concrete; (II ) it is a kind of inorganic material, with high interfacial bonding strength of concrete; (III ) basalt fiber in concrete has good dispersion and adhesion of fiber and concrete abnormal superior, the fiber reinforced concrete has better enhancement effects and limitations of fiber pull out the ability.

\section{Mechanical properties of basalt fiber reinforced concrete}

(1) compressive tensile mechanical properties: short basalt fiber on concrete compressive strength and splitting tensile strength and the influence of fiber content. The experimental results show that, basalt fiber volume fraction is $0.1 \%-0.2 \%$ of concrete compressive strength, splitting tensile strength and fibre rather basic, but in basalt fiber volume fraction is larger $(0.3 \%)$, and the compressive strength decreased about 13\%, splitting tensile strength decreased much more, were 40.38\%. Compressive strength, splitting tensile strength and decrease for two reasons: one is with the increase of fiber volume fraction, stirring in the process of basalt fiber is not easy to distribute uniformly in concrete and bond part into a group, in concrete caused some pores, thereby reducing the compressive strength, splitting tensile strength; the second is stirring, basalt fiber into powder, and water combination allows for and cement hydration water reduces, prevent the hydration of completely, which also caused the decrease of the strength of concrete. Test results also show that the basalt fiber delay the development of concrete at early age compressive strength and tensile strength, chopped basalt fiber reinforced concrete test $7 \mathrm{~d}$ compressive splitting tensile strength were $78.7 \%$ of the 28 day strength - $66.1 \%$, and the concrete matrix test $7 \mathrm{~d}$ compressive splitting tensile strength were $69.8 \%, 92.8 \%$ of the $28 \mathrm{~d}$ strength in addition, short basalt fiber is added to improve the ductility of concrete, inhibit the emergence and development of cracks in concrete.

(2) bending mechanical properties: flexural properties of basalt fiber reinforced concrete can best reflect the fiber reinforcing and toughening effect, the incorporation of basalt fiber in concrete bending performance enhancement, the flexural strength increased this is because in loading the initial stage, the fiber and the matrix shared loads, when the load continues to increase, by flexural tensile deformation to achieve initial fracture strain of fiber reinforced concrete, concrete cracks, across the crack fiber can still through the interfacial stress transfer, so that the flexural strength was improved to some extent, the flexural toughness has been significantly enhanced, and ordinary concrete once crack propagation will soon lead to a component of fracture. Experimental results show that when basalt fiber volume content is $1 \%$, the fiber reinforced concrete test bending tensile strength than that of the matrix concrete improves the $61.4 \%$, the flexural toughness index is 5.6 times of that of the concrete matrix, can be seen in the basalt fiber can significantly improve the concrete flexural strength and flexural toughness.

(3) anti impact properties: , basalt fiber is irregular and uniform in the concrete. this distribution in concrete form to the support system disorder and spatial network structure, absorbing the stress of concrete, and the bond between fiber and cement Xuan Wuyan colloid, shear failure of concrete fiber bear stress can play a blocking role blocks the development of micro cracks; and Xuan Wuyan fiber has good dispersion in concrete, fiber and concrete bonding exceptional, reinforcing and toughening effect and limitation of fiber pull-out ability of fiber reinforced concrete has better, so as to effectively enhance the toughness and impact resistance of concrete performance. The test results show that the impact when basalt fiber volume content of $0.1 \%$, the basalt fiber reinforced concrete flexural impact of early crack impact number $44 \%$ higher than that of plain concrete, while the flexural impact failure times than that of plain concrete was improved by $40 \%$, and explained that 
the basalt fiber in the reasonable dosage can significantly improve the concrete flexural impact performance.

(4) the durability of the mechanical properties: the study shows that the basalt fiber to the concrete wear resistance, corrosion resistance and other durability of the durability of a greater increase. The main contribution of basalt fiber on the abrasion resistance of concrete is the effect of crack resistance, the pore structure of concrete is improved, the harmless Kong Zengduo, reduce harmful holes, increasing compact performance of concrete, reduce the porosity; while in the wear process, fiber limit shows that basalt wear test of external force to the concrete matrix. The grinding strength increased $44.7 \% \sim 47.5 \%$ impact concrete with basalt fiber $28 \mathrm{~d}$, influence factors of concrete frost resistance is the most important of its density and pore structure characteristics, the incorporation of basalt fiber in concrete, a suppression of crack initiation, on the other hand, because of limited expansion of frozen produce, can effectively improve the the frost resistance of concrete. Experimental results show that the basalt fiber reinforced concrete relative dynamic elastic modulus in the process of freezing and thawing 100 times down to $71.55 \%$, and ordinary concrete relative dynamic elastic modulus decreased to $48.58 \%$, antifreeze performance is significantly better than that of ordinary concrete. The penetration of the concrete of harmful ions diffusion and hinder the ability depends on the concrete porosity and pore size distribution of, the basalt fiber in concrete is 3D chaos to distribute each other adhesion, played a role in supporting aggregate, effectively inhibited the generation the hardening of the concrete cracks, avoid the formation of pores connected, can improve the structure of cement stone, improve the concrete anti permeability, and effectively improve the corrosion resistance of concrete.

\section{Conclusion}

Basalt fiber green price high performance concrete and good compatibility and adding to concrete can improve the mechanical properties of concrete, is a worthy of promotion and application of the novel fiber reinforced materials, in order to further broaden its application in concrete engineering, should also pay attention to the following questions:

(1) the general concrete from the cracks to the complete failure process is very short, there is no buffer process, it is obvious brittle failure. After adding basalt fiber, the failure process of the specimens is relatively slow, showing the characteristics of plastic failure. The failure mode directly determines the mechanical properties of the material. Therefore, it is necessary to study the failure mode of basalt fiber reinforced concrete.

(2) experimental study showed that fiber mixing amount of concrete compressive strength and flexural strength of the impact is not as dosage increases and monotonically enhances, the fiber content of the optimal value of has a direct impact on the mechanical properties of basalt fiber reinforced concrete.

(3) experimental study show that basalt fiber reinforced concrete of preparing process on the mechanical properties is also great, common basalt fiber concrete preparation is divided into the following three forms: straight addition method that direct incorporation, presaturation method and cement paste coating method. The influence of the three processes on the mechanical properties must be considered.

(4) Basalt fiber reinforced concrete can be regarded as composite fiber concrete, stress and elastic modulus of composite material applied theory of fiber reinforced concrete. And consider the relationship between content and mechanical properties of fiber reinforced concrete and fiber orientation, length diameter ratio and fiber and matrix adhesion.

\section{References}

[1] Li Jianjun, the party XinAn basalt fiber preparation [J]. Synthetic fiber industry, 2007,30 (2) :35-37.

[2] Ouyang Lijun Ding Bin Lu Chau guide. Basalt fiber and its applied research in the 
reinforcement of building structures [J]. Glass fiber reinforced plastic / composite materials, 2010 (3): 84-88.

[3] Yang Yongxin, Yang Meng, Zhao Yan basalt fiber cloth in a durability test [J]. Industrial Construction, 2007, 37 (6): 11-13.

[4] Wu Gang, Wei Yang, Lactic deep basalt fiber and carbon fiber reinforcement on the seismic performance of concrete rectangular Comparative Study [J]. Industrial Construction, 2007, 7 (6): 42-46.

[5] Li Zhiqiang, Ma Jian lock, Bai Yun Mountain basalt fiber cloth to improve the reinforced concrete beam shear capacity tests [J]. Hebei Institute of Architectural Engineering, 2008, 26 (3) :72-81.

[6] Wu Di, Shao-liang. Properties and application of basalt fiber reinforced concrete [J]. Subgrade, 2010, (2) :37-39.

[7] Chen Feng. Basalt fiber concrete development and research prospects [J]. Fujian Building Materials, 2011, (5) :8-9.

[8] Liao Christina Xu Tingting, Qian Wei. Basalt fiber concrete technical performance [J]. Foreign Highway, 2012,32 (3) :320-324.

[9] Wu RH. The Application of Basalt Fiber in Building Materials [J]. Trends in Building Materials Research, 2012, 450-451:499-502.

[10] Bang Tu ye, Jin Yang Jiang. Basalt fiber and reinforced cement based materials research progress [J]. Materials herald a: review article, 2013, 27 (10): 102-108 